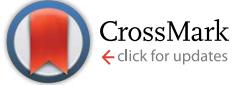

Cite this: RSC Adv., 2017, 7, 4941

Received 7th November 2016 Accepted 4th January 2017

DOI: 10.1039/c6ra26439e

www.rsc.org/advances

\section{Synthesis and application of a new class of $D-\pi-A$ type charge transfer probe containing imidazole - naphthalene units for detection of $\mathrm{F}^{-}$and $\mathrm{CO}_{2} \dagger$}

\author{
Ramesh C. Gupta, Rashid Ali, Syed S. Razi, Priyanka Srivastava, Sushil K. Dwivedi \\ and Arvind Misra*
}

\begin{abstract}
A new class of D- $\pi-A$ type charge transfer probe, 3 and 4 , containing imidazole - naphthalene moieties as donor and acceptor, respectively, has been synthesized via a Suzuki coupling reaction. Probe 3, upon interaction with different classes of anions, showed high selectivity toward fluoride with a detection sensitivity of $4 \mathrm{ppb}(0.22 \mu \mathrm{M})$. The in situ generated imidazolyl ion $\left(3+\mathrm{F}^{-}\right)$enables the detection of $\mathrm{CO}_{2}$ with the restoration of the original absorption and emission properties of 3 . The mode of interaction has been confirmed by ${ }^{1} \mathrm{H}$ NMR and DFT studies which suggested the deprotonation of the $-\mathrm{NH}$ fragment of the imidazolyl unit in the presence of $\mathrm{F}^{-}$.
\end{abstract}

\section{Introduction}

In recent years the scientific community has shown much interest in developing specific molecular organic scaffolds for the selective recognition of anions that have serious unfavorable effects on organisms. ${ }^{1}$ In the family of different classes of anions the $\mathrm{F}^{-}$anion has gained much importance in dental care, treatment of osteoporosis, and treatment of drinking water. Also fluoride has been used as in anesthetics, hypnotic and psychiatric drugs, military nerve gases and in the refinement of uranium. ${ }^{2-6}$ The Environmental Protection Agency (EPA, USA) has set a standard of 2-4 ppm to protect individuals against several disorders. ${ }^{7}$ Over-exposure to fluoride may cause serious health problems such as, fluorosis, neurological and metabolic disorders ${ }^{8-12}$ and even cancer like osteosarcoma. ${ }^{13}$ Therefore, it is highly important to develop selective, sensitive, fast, and cost-effective detection methods for fluoride anions.

The selective recognition of specific anion is challenging because of their lower charge to radius ratio, microenvironment sensitivity (solvent effect), $\mathrm{pH}$ sensitivity, as well as their existence in a wide range of different geometries. ${ }^{14}$ Particularly, fluoride has smallest ionic radius, highest charge density, and has hard Lewis base nature. ${ }^{\mathbf{1 4}}$ The conventional analytical methods for $\mathrm{F}^{-}$typically involve the use of ion chromatography, ${ }^{15}$ ion-selective electrodes, ${ }^{16,17}$ and capillary zone electrophoresis. ${ }^{18}$ Moreover, among widely used sensing techniques for the detection of anions optical based methods such as

Department of Chemistry, Institute of Science, Banaras Hindu University, Varanasi-221005, UP, India.E-mail: arvindmisra2003@yahoo.com; amisra@bhu. ac.in

$\dagger$ Electronic supplementary information (ESI) available. See DOI: 10.1039/c6ra26439e application of chemosensors (chromo or fluorogenic) has recently emerged as the most convenient technique due to high selectivity, sensitivity and naked eye visibility, low detection limit and suitability for detection at the intracellular and tissuespecific level. ${ }^{19}$

Recently great efforts have been made to develop suitable molecular scaffolds to detect fluoride based on different photophysical processes. ${ }^{20}$ However, molecular scaffolds based on intramolecular charge transfer (ICT) and ratiometric fluorescence responses are in great demand. Ratiometric systems have advantages because it allows simultaneous response at two wavelengths. Thus, to make non-covalent recognition event thermodynamically feasible and convenient to the naked-eyes for a target anion there is a great need to develop a specific molecular scaffold based on binding site signaling approach by incorporating a suitable chromophore and a neutral anion receptor unit such as $-\mathrm{NH}$ fragment. ${ }^{21}$ This is also because both fluoride and carboxylate anions easily interact with - $\mathrm{NH}$ fragment through a strong hydrogen-bond interaction in an aprotic medium. Moreover, the presence of hetero atoms in synthetic polycyclic aromatic hydrocarbons of high planarity enable better electron delocalization and generates good photophysical properties, such as, intense fluorescence due to high charge mobility. ${ }^{22-27}$ Thus, the typical structural and electronic changes encountered upon anion-receptor interaction by directional hydrogen bonding and/or by donation of one or more hydrogens of $\mathrm{NH}$ fragment to the anion are easy to follow by spectroscopic techniques. ${ }^{28}$

Additionally, among the gases $\mathrm{CO}_{2}$ is an important greenhouse gas which is a major factor for global climate change as well as has vital role in human physiology and diagnostic applications in medical science. ${ }^{29-37}$ Thus, the sensitive detection of $\mathrm{CO}_{2}$ has great significance. Recently it has been found 
that anionic amine, carbene and anionic amide are suitable substrate to demonstrate unique anion-activated $\mathrm{CO}_{2}$ sensing through a simple colorimetric and fluorescent change. ${ }^{38-40}$

In view of above facts and in continuation to our previous efforts in the area of molecular recognition ${ }^{41}$ we herein report a new class of organic scaffold for selective detection of fluoride and $\mathrm{CO}_{2}$ in DMSO. In our previous contribution we have developed some $\mathrm{D}-\pi-\mathrm{A}$ type organic scaffolds in which the phenyl substituted imidazolyl and benzothiazole moieties are linked with a phenyl and/or thiophene unit and realized their application in the detection of anions, cations and $\mathrm{CO}_{2}$. In fact, planar polycyclic aromatic hydrocarbons facilitate better photophysical properties due to extended conjugation, high extent charge mobility and their mutual arrangement with in the molecule. ${ }^{42}$ Further, to develop a more selective and sensitive probe for a target anion, we consciously extended $\pi$-conjugation by conjugating phenyl substituted imidazolyl and naphthalene moieties through a phenyl bridge. The newly synthesized D- $\pi-\mathrm{A}$ type molecular probe, 3 showed good optical behavior based on intramolecular charge transfer (ICT) process in which, imidazolyl and naphthalene units worked as donor and acceptor, respectively. As expected, upon interaction with different class of anions in DMSO the -NH fragment of imidazole unit of probe 3 interacted with $\mathrm{F}^{-}$selectively through $\mathrm{H}$-bonding interaction followed by deprotonation and exhibited naked-eye sensitive colorimetric changes and fluorescence "turn-on" response ratiometrically, due to charge transfer/propagation between donor and acceptor moieties by push-pull mechanism. Moreover, the anionic fluoroionophore moiety, $3+\mathrm{F}^{-}$has been successfully utilized to detect and estimate $\mathrm{CO}_{2}$ with high sensitivity and unique chromo and fluorogenic responses.

\section{Results and discussion}

\subsection{Synthesis and photophysical behavior of probe 3}

The synthesis of probe $\mathbf{3}$ and the model compound $\mathbf{4}$ were synthesized as shown in Scheme 1 . The imidazole derivative 1 and 2 was obtained in good yield by one pot multi-component reaction process. ${ }^{43}$ Compound 1 was synthesized by reacting $p$-bromobenzaldehyde, benzil and $\mathrm{NH}_{4} \mathrm{OAc}$ in glacial acetic acid while for 2, aniline was refluxed along with $p$-bromobenzaldehyde, benzil and $\mathrm{NH}_{4} \mathrm{OAc}$ in glacial acetic acid. Now compound

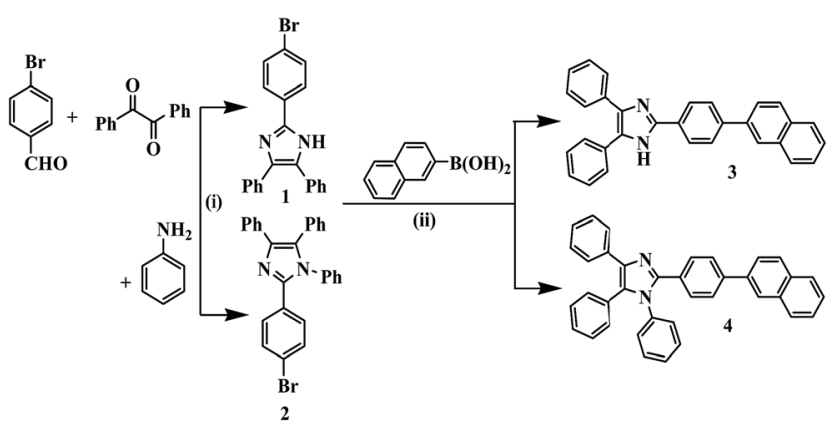

Scheme 1 (i) $\mathrm{CH}_{3} \mathrm{COONH}_{4} /$ acetic acid $/ 110{ }^{\circ} \mathrm{C}$ (ii) $\mathrm{Pd}(\mathrm{OAC})_{2} / \mathrm{TBAB} /$ $\mathrm{K}_{2} \mathrm{CO}_{3} / \mathrm{H}_{2} \mathrm{O}$.
1 and 2 were reacted with naphthalene-2-boronic acid using Suzuki coupling reaction protocol ${ }^{44}$ to get desired products 3 and $\mathbf{4}$ in quantitative yield. The compounds were characterized by ${ }^{1} \mathrm{H}$ NMR, ${ }^{13} \mathrm{C}$ NMR, IR and TOF-MS spectroscopy data (Fig. S1-S12, ESI $\dagger$ ).

2.1.1 Photophysical behavior of probe 3 in solid state and anion selectivity. We first examine the behavior of 3 in solid state. Upon excitation at $340 \mathrm{~nm} 3$ showed weak emission at $432 \mathrm{~nm}$ and upon interaction with different anions such as, $\mathrm{Cl}^{-}$, $\mathrm{Br}^{-}, \mathrm{I}^{-}, \mathrm{AcO}^{-}, \mathrm{CN}^{-}$and $\mathrm{F}^{-}$(as their tetrabutylammonium salt) displayed change with $\mathrm{F}^{-}, \mathrm{CN}^{-}$and $\mathrm{AcO}^{-}$in which the emission band centered at $432 \mathrm{~nm}$ disappeared completely and new emission bands appeared at 521, 520 and $502 \mathrm{~nm}$ respectively (Fig. 1b). Notably, the solid state reaction resulting in an instantaneous color change from brown to yellow when crystals of tetrabutylammonium fluoride (TBAF) and tetrabutylammonium cyanide (TBACN) are brought (even without grinding) in contact with probe 3 (Fig. 1a). However, under UV-light, nonfluorescent probe 3 with TBAF and TBACN displayed bright fluorescent yellow color while relatively weak greenish yellow color was observed with TBOAc. The other tested anions failed to exhibit any significant change. The specificity for $\mathrm{F}^{-}, \mathrm{CN}^{-}$ and $\mathrm{AcO}^{-}$anions appears to be due to their higher basicity among the anions. Moreover, the probe 4 which do not have active - $\mathrm{NH}$ fragment, upon interaction with tested anions showed insignificant change. Thus, suggesting that proton on imidazole $\mathrm{N}$ atom is important for reaction and sensing. ${ }^{40}$

2.1.2 Photophysical behavior of probe 3 in solution and anion selectivity. Next we examined the photophysical properties of probe $\mathbf{3}$ and $\mathbf{4}$ in solvents of different polarity (Tables S13 and $\mathrm{S} 14 \dagger$ ) and found that DMSO is better system to carry out further studies (Fig. S15 and S16 $\dagger$ ). UV-vis spectrum of $3(10 \mu \mathrm{M})$ in DMSO showed an intramolecular charge transfer (ICT) band at $340 \mathrm{~nm}\left(\varepsilon=4.29 \times 10^{4} \mathrm{M}^{-1} \mathrm{~cm}^{-1}\right)$. Similarly, upon excitation at $340 \mathrm{~nm} 3$ showed emission maxima at $448 \mathrm{~nm}\left(\Phi_{3}=0.585\right)$ with Stokes shift of $\sim 108 \mathrm{~nm}$. Further, to ensure the selectivity of probe 3 toward anions in solution absorption and emission spectra has been examined. Notably, upon interaction with different anions (50 equiv.) such as, $\mathrm{Cl}^{-}, \mathrm{Br}^{-}, \mathrm{I}^{-}, \mathrm{AcO}^{-}, \mathrm{CN}^{-}$and $\mathrm{F}^{-}$(as their tetrabutylammonium salt) 3 displayed high selectivity for $\mathrm{F}^{-}$in which the ICT band disappeared completely and a new transition band appeared at $390 \mathrm{~nm}\left(\varepsilon=2.49 \times 10^{4} \mathrm{M}^{-1}\right.$ $\mathrm{cm}^{-1}$ ) and a naked-eye sensitive orange yellow color appeared in
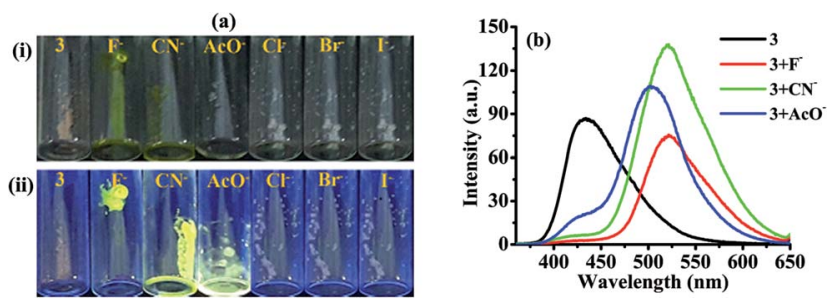

Fig. 1 (a) Images (i) under visible light (ii) under UV-light (365 nm) showed solid state color change of probe 3 in the absence and presence of $\mathrm{F}^{-}, \mathrm{CN}^{-}, \mathrm{AcO}^{-}, \mathrm{Cl}^{-}, \mathrm{Br}^{-}$, and $\mathrm{I}^{-}$ions. (b) Solid state emission spectra of probe 3 with $\mathrm{F}^{-}, \mathrm{CN}^{-}$, and $\mathrm{AcO}^{-}$. 

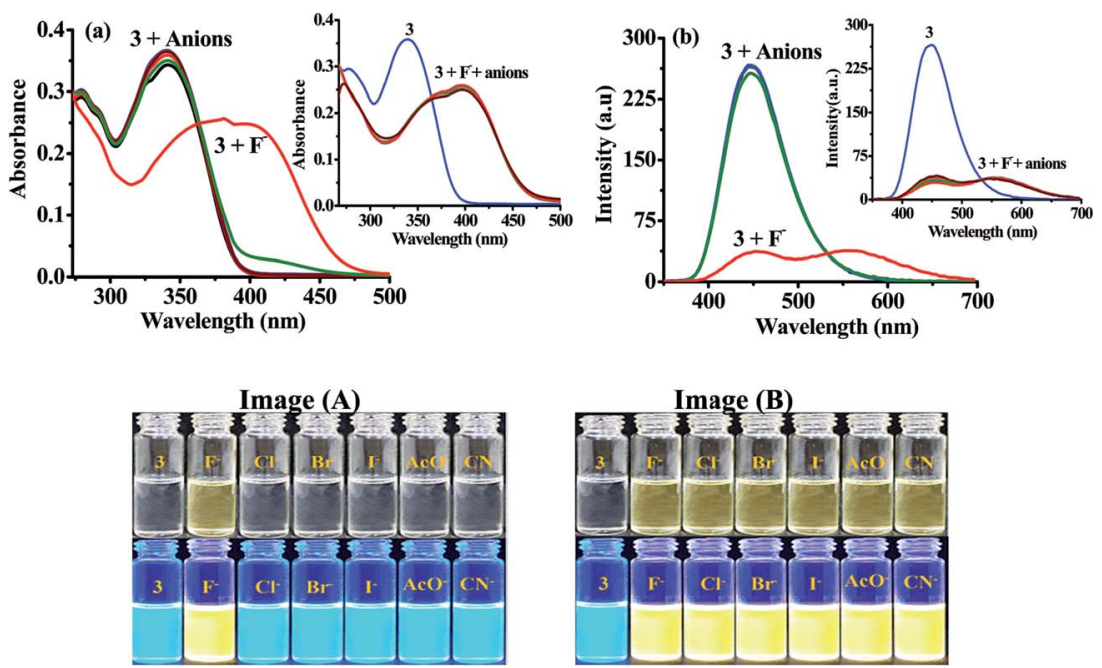

Fig. 2 (a) Absorption $(10 \mu \mathrm{M})$ and (b) emission spectra of $3(10 \mu \mathrm{M})$ upon interaction with tested anions (50.0 equiv.) in DMSO. Insets: absorption and emission spectra of $3+\mathrm{F}^{-}$upon interference with competitive anions (60.0 equiv.). Images: change in color of 3 (10 $\left.\mu \mathrm{M}\right)$ upon interaction (Images A) and interference (Images B) with different anions.

the solution (Fig. 2a). Similarly, upon interaction with $\mathrm{F}^{-}$the fluorescence intensity of $3\left(10 \mu \mathrm{M}, \lambda_{\mathrm{ex}}=340 \mathrm{~nm}\right)$ centered, at $448 \mathrm{~nm}$ diminished and a dual emission band appeared at 453 and $565 \mathrm{~nm}\left(\Phi_{3+\mathrm{F}^{-}}=0.26\right)$ (Fig. 2b). Moreover, the naked eye sensitive intense blue-green color of 3 , under UV light, switched-on to a light yellow color upon interaction with $\mathrm{F}^{-}$ (Fig. 2, images A). The interaction with other tested anions revealed insignificant change in the photophysical behavior of 3. However upon increasing the concentration of anions (150 equiv.) $\mathrm{CN}^{-}$also showed considerable fluorescence quenching while quenching observed with $\mathrm{AcO}^{-}$anion remained marginal
(Fig. S17, ESI†). Further to ascertain high selectivity of 3 toward $\mathrm{F}^{-}$competitive anion interference studies have been performed by the addition of excess of tested anions (60 equiv.) to a probable solution of $3+\mathrm{F}^{-}$and reversibly, by the addition of $\mathrm{F}^{-}$to a solution of 3 containing another tested anions. Insignificant change in the absorption and emission spectrum of $3+\mathrm{F}^{-}$ suggested about the high selectivity of 3 for $\mathrm{F}^{-}$(Inset of Fig. 2a, $\mathrm{b}$ and Images B).

Further, the binding affinity of 3 toward $\mathrm{F}^{-}$has been realized through the absorption and emission titration experiments (Fig. 3). Upon a gradual addition of $\mathrm{F}^{-}(0-40$ equiv.) to a solution
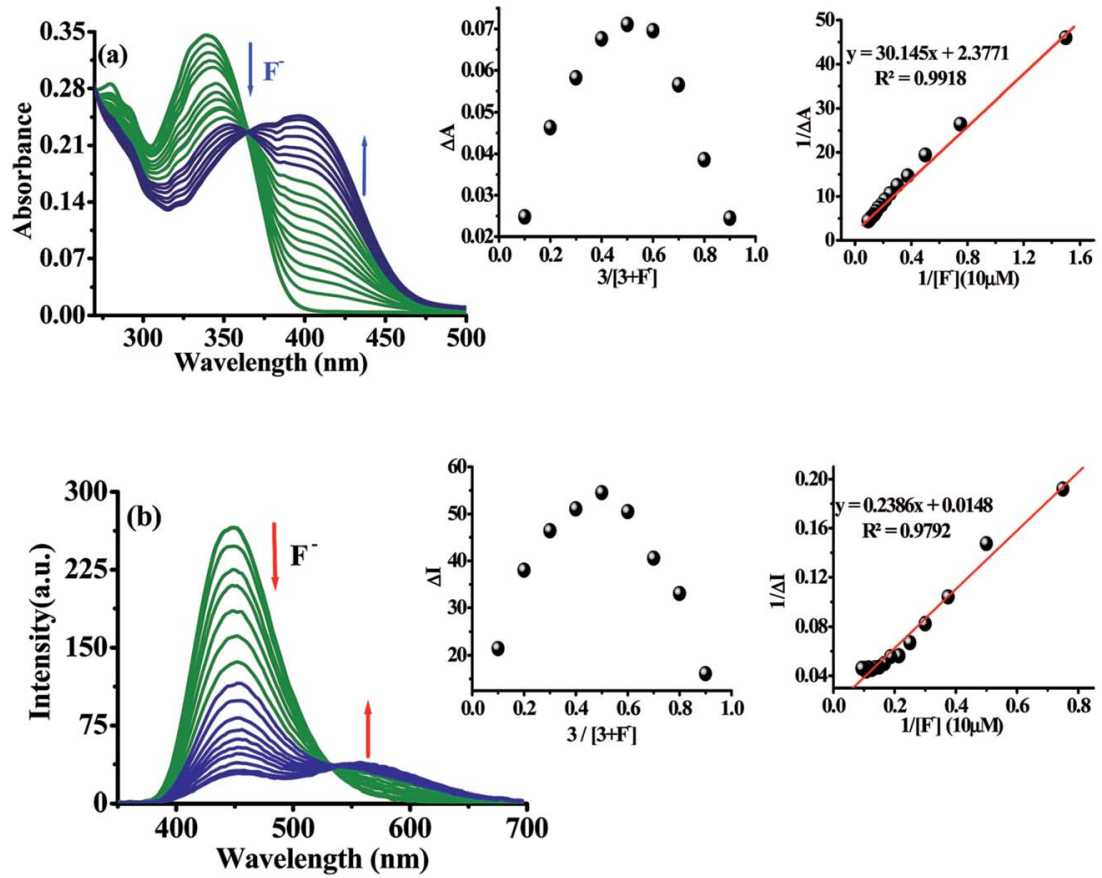

Fig. 3 Absorption $(10 \mu \mathrm{M})(\mathrm{a})$ and emission (b) at $\lambda_{\mathrm{ex}}=340 \mathrm{~nm}$ titration spectra of $3(10 \mu \mathrm{M})$ upon sequential addition of $\mathrm{F}^{-}(0$ to 40 equiv.) in DMSO. Insets: Job's plot and B-H plots based on (a) absorption and (b) emission spectra. 
of 3 the absorption spectra displayed ratiometric behavior in which band centered, at $340 \mathrm{~nm}$ decreased while the absorption of a new band at $390 \mathrm{~nm}$ enhanced concomitantly (Fig. 3a). Similarly, the emission titration studies displayed ratiometric behavior in which fluorescence intensity of 3 (at, $\lambda_{\mathrm{ex}}=340 \mathrm{~nm}$ ), centered at $448 \mathrm{~nm}$ diminished gradually and two new emission bands appeared at $453 \mathrm{~nm}$ and $565 \mathrm{~nm}$ (Fig. 3b). The appearance of isosbestic and isoemissive points at 365 and $532 \mathrm{~nm}$, respectively clearly supported about the existence of more than one species in the medium. The observed significant red shift in the photophysical behavior of 3 upon interaction with $\mathrm{F}^{-}$is attributed to enhance intramolecular charge transfer encounter due to deprotonation of - $\mathrm{NH}$ fragment. ${ }^{45-48}$ The reaction stoichiometry between 3 and $\mathrm{F}^{-}$has been realized by obtaining the absorption and emission spectra as a function of $\mathrm{F}^{-}$concentration. The maxima at 0.5 mole fractions suggested about a $1: 1$ stoichiometry for a probe-fluoride interaction. For which, the binding constant has been estimated through Benesi-Hildebrand (B-H) $\operatorname{method}^{49}$ and were found to be $K_{\text {ass }}(\mathrm{abs})=7.90 \times 10^{3} \mathrm{M}$ and $K_{\text {ass }}(\mathrm{em})=6.2 \times 10^{3} \mathrm{M}$ respectively (inset of Fig. $3 \mathrm{a}$ and b).

The limit of detection (LOD) of probe 3 for $\mathrm{F}^{-}$has been estimated as reported previously. ${ }^{50}$ An approximately straight line calibration curve, obtained by taking the emission spectra of 3 at different concentration ( 1.0 to $0.1 \mu \mathrm{M})$ suggested about a linear correlation between intensity and concentrations of the probe with standard deviation 0.90 (Fig. 4a). Further, from the slope of the fluorescence curve, obtained between $\Delta I\left(I-I_{0}\right)$ (where $I_{0}$ and $I$ illustrate the emission intensities of 3 in the presence and absence of $\mathrm{F}^{-}$) and concentration of the anions in the aforementioned range, the calibration sensitivity $(m)$ was estimated and was found to be 12.099 (Fig. 4b). Now employing eqn (3) the limit of detection (LOD) for $\mathrm{F}^{-}$was calculated and was found to be $0.22 \mu \mathrm{M}$ which is well below the recommended level and comparable to other reported methods. ${ }^{51}$

\section{2 pH study of probe 3 in HEPES buffer}

The photophysical behavior displayed by 3 in the presence of $\mathrm{F}^{-}$ suggested about the deprotonation of - $\mathrm{NH}$ fragment of imidazolyl unit ${ }^{45-48}$ consequently, the observed ratiometric enhanced emission is attributed to polarization and/or charge propagation of an increase electron density on the imidazolyl unit. Moreover, the moderately weak acidic - $\mathrm{NH}$ function of imidazole unit is susceptible to protonation and deprotonation under acidic and alkaline $\mathrm{pH}$. Therefore, to rationalize the effect
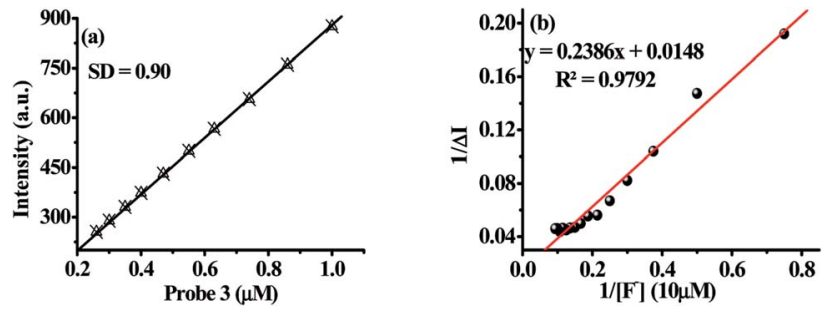

Fig. 4 (a) Calibration curve for 3 and (b) calibration sensitivity plot of 3 for $\mathrm{F}^{-}$.
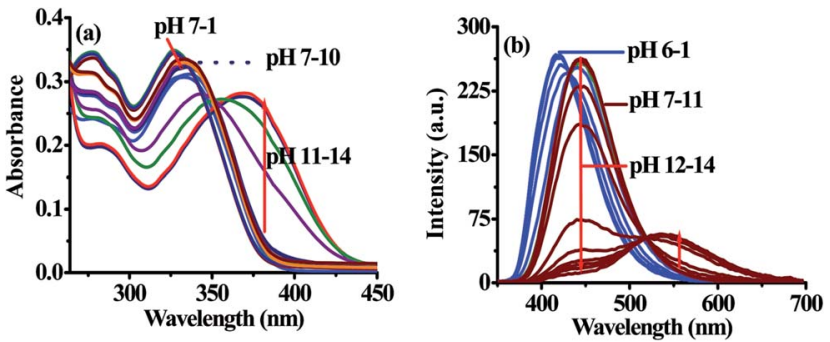

Fig. 5 Change in absorption (a) and emission (b) spectra of $3(10 \mu \mathrm{M})$ at different $\mathrm{pH}$ in HEPES buffer.

of $\mathrm{F}^{-}$, pH dependent photophysical behavior of 3 was investigated in HEPES buffer (10 mM, pH 7.04; 40\% aqueous DMSO).

The absorption spectrum of $3(10 \mu \mathrm{M})$ showed electronic transition bands at $340 \mathrm{~nm}\left(\varepsilon=3.35 \times 10^{4} \mathrm{M}^{-1} \mathrm{~cm}^{-1}\right)$ (Fig. 5a). Similarly, upon excitation at $340 \mathrm{~nm}$ probe 3 showed intramolecular charge transfer emission band at $448 \mathrm{~nm}$ (Fig. 5b). Notably, under acidic (pH 7 to 6) conditions the molar absorptivity of 3 increased and new band appeared at $326 \mathrm{~nm}(\varepsilon=3.50$ $\times 10^{4} \mathrm{M}^{-1} \mathrm{~cm}^{-1}$; blue-shift, $\left.\sim 14 \mathrm{~nm}\right)$ and remain constant at $\mathrm{pH}$ 6 to 1 wherein alkaline ( $\mathrm{pH} 10$ to 14 ), the band centered, at $340 \mathrm{~nm}$ disappeared and a new transition band appeared at $370 \mathrm{~nm}\left(\varepsilon=2.79 \times 10^{4} \mathrm{M}^{-1} \mathrm{~cm}^{-1}\right.$; red-shift, $\left.\sim 30 \mathrm{~nm}\right)$ (Fig. 5a). The formation of isosbestic points at 334 and $352 \mathrm{~nm}$ in acidic and alkaline medium, respectively suggested about the existence of more than one species in the medium. Similarly, under acidic $\mathrm{pH}(7-6)$ the emission intensity of 3 centered at $445 \mathrm{~nm}\left(\lambda_{\text {ex }}=340\right.$ $\mathrm{nm}$ ) increased with a blue shift of $\sim 27 \mathrm{~nm}$ while under alkaline $(>11)$ condition dual emission band appeared at $440 \mathrm{~nm}$ (blue shift $\sim 5 \mathrm{~nm}$ ) and $545 \mathrm{~nm}$ (red shift $\sim 100 \mathrm{~nm}$ ) (Fig. 5b) and the color of solution become yellowish orange. Thus, acid-alkali titration studies clearly supported about the protonation-deprotonation of the probe in the medium.

\subsection{Nature of interaction between 3 and $F^{-}$}

To get a deep insight about actual mechanism of interaction between 3 and $\mathrm{F}^{-}$the ${ }^{1} \mathrm{H}$ NMR studies have been performed DMSO- $d_{6} \cdot{ }^{1} \mathrm{H}$ NMR spectrum of $3\left(2.0 \times 10^{-2} \mathrm{M}\right)$ (Fig. 6) showed aromatic protons resonance in the range at $\delta 8.35-7.25 \mathrm{ppm}$. The imidazolyl $-\mathrm{NH}$ resonance appeared at $\delta 12.78(\mathrm{~s}) \mathrm{ppm}$ due to hydrogen bonding interaction with solvent DMSO- $d_{6}$. Upon addition of $\mathrm{F}^{-}(0-2.0$ equiv.) to a solution of 3 the $-\mathrm{NH}$ resonances broadened. Further addition of 3.0 to 5.0 equiv. of $\mathrm{F}^{-}$the -NH resonances disappeared completely and the resonances of phenyl ring proton shifted up field. A broad band appeared at $\delta 16.05$ ppm suggested about the formation of $\mathrm{HF}_{2}{ }^{-}$species ${ }^{35-37}$ in the medium. Thus, the proton NMR studies clearly favored about the $\mathrm{H}$-bonding interaction between - NH fragment of $\mathbf{3}$ and $\mathrm{F}^{-}$followed by deprotonation. Consequently, the ICT increased due to charge propagation from imidazole to naphthalene unit.

\subsection{DFT calculation}

The geometry optimization and quantum chemical calculations for $\mathbf{3}$ and the corresponding deprotonated product, 5 were 


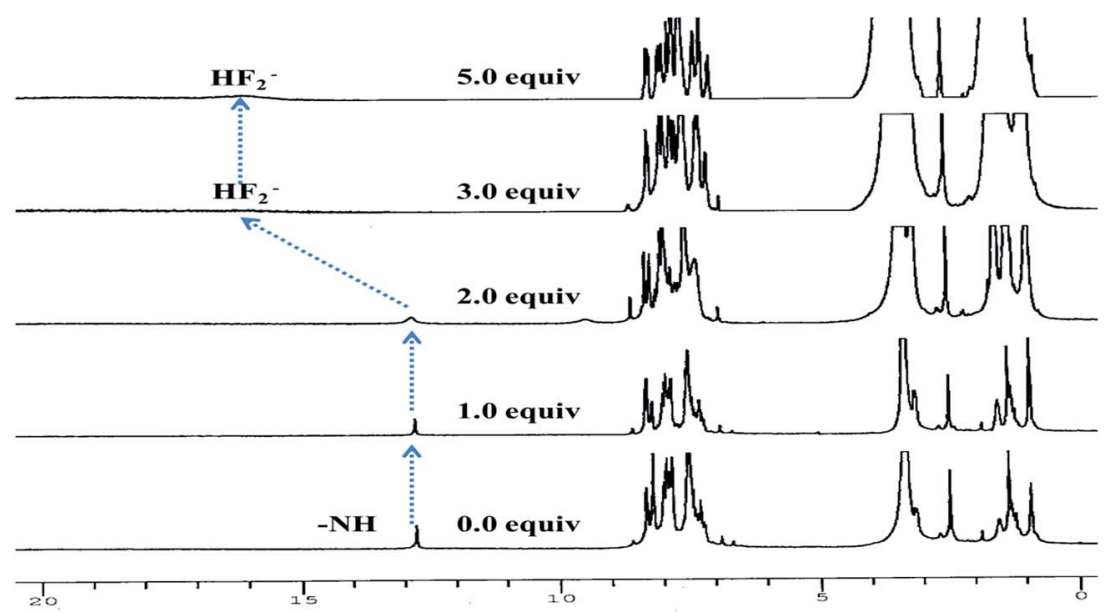

Fig. 6 Stacked ${ }^{1} \mathrm{H}$ NMR spectra of $3\left(2.0 \times 10^{-2} \mathrm{M}\right)$ upon addition of $\mathrm{F}^{-}(0-5.0$ equiv. $)$ in DMSO- $d_{6}$.

performed by density functional theory (DFT) method as implemented in Gaussian 03 suits of program ${ }^{51}$ employing basis set B3LYP/6-31G*. As shown in (Fig. 7), the relevant occupied molecular orbital, HOMO $(-0.30922 \mathrm{eV})$ is delocalized to the entire unit probe 3 , in which the electron density is spread over the imidazole-phenyl bridge-naphthalene unit while unoccupied molecular orbital LUMO $(-0.22094 \mathrm{eV})$ are distributed more towards naphthalene-phenyl unit. Similarly, for 5 the
HOMO $(-0.29103 \mathrm{eV})$ is located to the entire unit while LUMO $(-0.21889 \mathrm{eV})$ is more localized to naphthalene-phenyl bridge. Thus, the molecular orbital approximation favors about the intramolecular charge transfer (ICT) from imidazole to naphthalene unit. The deprotonation of imidazolyl $-\mathrm{NH}$ led to a further polarization in electron density from the imidazole to naphthalene unit. Furthermore, the energy gap between the HOMO and LUMO of $5(\Delta E=0.07214 \mathrm{eV})$ was found less than

[A]

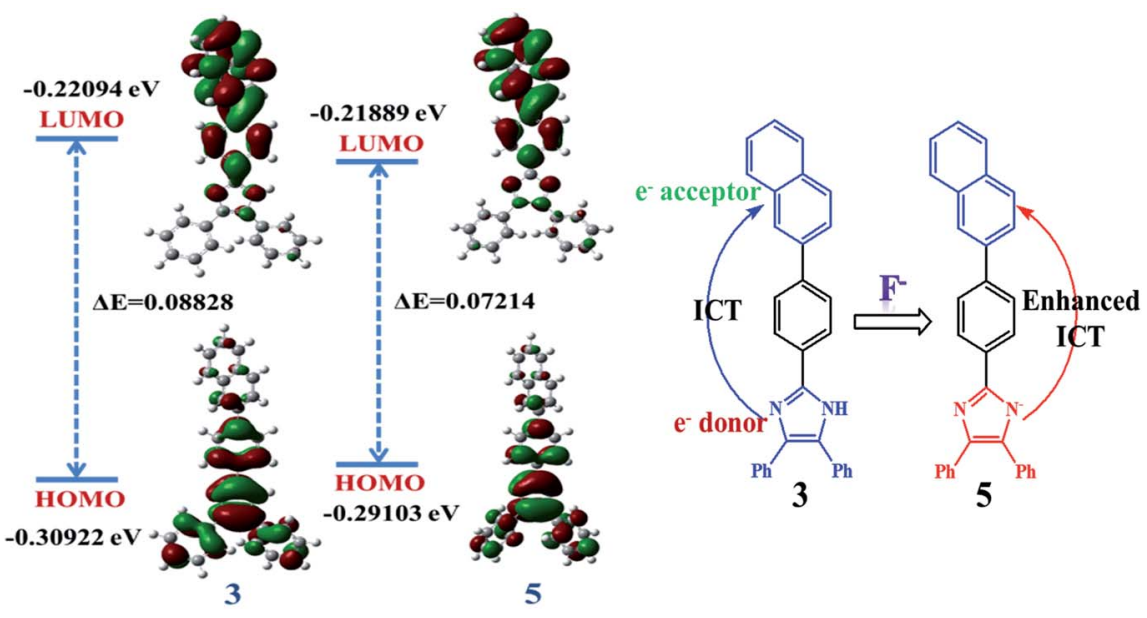

[B]
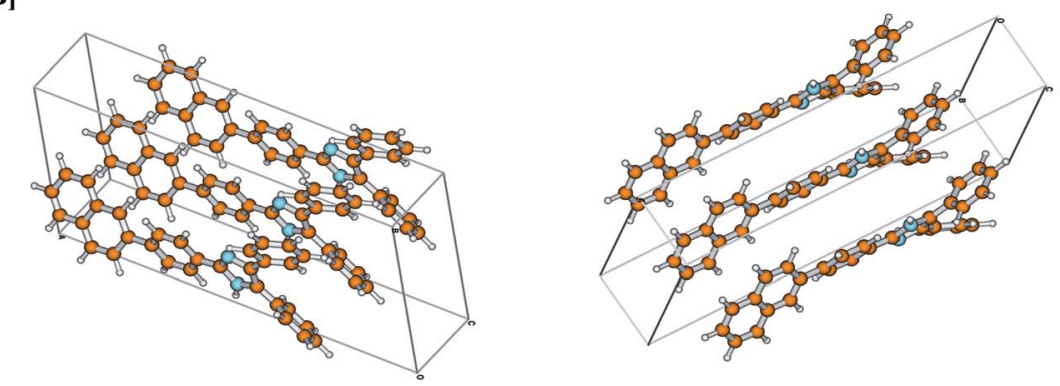

Fig. 7 [A] DFT optimized minimum energy structures and HOMO-LUMO energy difference between 3 and 5 and proposed mechanism of interaction between probe 3 and $\mathrm{F}^{-}$. [B] DFT optimized packing arrangement of probe 3 . 
that of probe $3(\Delta E=0.08828 \mathrm{eV})$ and in good agreement with the red shift observed in the absorption spectra upon treatment with $\mathrm{F}^{-}$. Thus both the theoretical and experimental observations corroborated the possible mode of interaction between 3 and fluoride anion.

Further, in DMSO the basic nature of anions follow the order $\mathrm{F}^{-}>\mathrm{CN}^{-}>\mathrm{AcO}^{-}>\mathrm{H}_{2} \mathrm{PO}_{4}^{-}>\mathrm{BzO}^{-}>\mathrm{Cl}^{-}>\mathrm{HSO}^{-}>\mathrm{SCN}^{-}>$ $\mathrm{NO}_{3}{ }^{-}>\mathrm{Br}^{-}>\mathrm{I}^{-}$which is in general agreement with the Hofmeister series and reported methods. ${ }^{52}$ Fluoride is the most basic anion, and the following one is the cyanide. The different emission behavior of probe toward tested anions in solid and solution is possible and are known. The molecules in the solid state hardly move at all reactions are also very slow because molecules can't easily come into contact with each other. If two solids are mixed, molecules on the surface of the solid grains may react, but the molecules buried inside will be left untouched. In the solid state the stoichiometric ratio between the probe and tested anions are not maintained this could be a reason to get exceptionally variable enhancement in the intensities despite of the basicity order of the tested anions but enhancement in emission toward high wavelength was observed with anions such as $\mathrm{CN}^{-}, \mathrm{AcO}^{-}$and $\mathrm{F}^{-}$that could be understood considering the formation of aligned dimeric aggregate or excimer formation due to better aligned packing arrangement and/or lattice fit between the deprotonated and neutral molecules due to $\pi-\pi$ and H-bonding interactions. Although we failed to obtain crystal of the molecule and its probable complex but minimum energy structure obtained through DFT method suggested about the planarity and dimeric alignment of the molecule (Fig. 7B).

In recent years we and others have demonstrated modulations in photophysical behavior of anion-responsive probes induced by fluoride in organic solvents, which usually originate either due to hydrogen-bonded complex formation (in early transition stage) and deprotonation (later stage) steps. ${ }^{\mathbf{4 6 - 4 8 , 5 3}}$ To explain the fluorescence quenching of ICT emission of the probe in solution size, basicity and solvation factor of the concerned anions are decisive. In solution intensity of probe drastically decreases at $448 \mathrm{~nm}$ with $\mathrm{F}^{-}$only, upon using around 50-60 equiv. of all the tested anions. However when we increased the concentration of anions probe also showed some affinity with $\mathrm{CN}^{-}$and $\mathrm{AcO}^{-}$anions also probably due to hydrogen bonding interaction. But change in optical behavior was more pronounced with $\mathrm{F}^{-}$obviously due to smaller size and high basicity that ultimately leads to deprotonation of the probe. Consequently, the diminished emission observed at $448 \mathrm{~nm}$ is clearly due to enhanced ICT process. On other side with a rise in electron density on the naphthalene moiety, due to charge propagation, would certainly increase the probability of $\pi-\pi$ interaction along with enhanced $\mathrm{H}$-bonding interactions between the deprotonated and neutral species. Thus, the possibility of unstructured excimer emission or emission due to aggregate formation can be understood and should be rationalized and justify to emission observed at $565 \mathrm{~nm}$ which showed more red shift than the enhanced emission observed in solid state at $\sim 502-521 \mathrm{~nm}$. The low intensity of excimer emission observed at $565 \mathrm{~nm}$ may considered by accounting the intermolecular H-bonding with DMSO solvent. Moreover in solution the low intensity of emission observed at $565 \mathrm{~nm}$ is obviously is due to the intermolecular H-bonding interaction with the solvent.

\subsection{Detection of $\mathbf{F}^{-}$on cellulose paper strips}

In order to make sure the potential applicability of probe 3 to detect fluoride anion on test paper strips, small cellulose paper strips (Whatman ${ }^{\mathrm{TM}}$ ) containing different concentration of $\mathbf{3}$ (5, 2 and $1 \mathrm{mM})$ were prepared $\left(1.5 \times 2.0 \mathrm{~cm}^{2}\right)$ in acetone. The dried test paper strips were dipped in different concentration solutions of $\mathrm{F}^{-}\left(10 \times 10^{-5}, 5 \times 10^{-5}\right.$, and $1 \times 10^{-5} \mathrm{M}$; of TBAF in ACN) for $5 \mathrm{~min}$ and then the air dried strips were visualised under UV light (at $365 \mathrm{~nm}$ ). The visibility of color on the strip was good up to $1 \mathrm{mM}$ level in which color of paper strips were changed from blue to green (under UV light at $365 \mathrm{~nm}$ ) (Fig. 8a). The paper strip could able to detect $\mathrm{F}^{-}$up to $10^{-6} \mathrm{M}$ concentration. The paper strips of 0.1 and $0.01 \mathrm{mM}$ concentration of probe could also able to detect $\mathrm{F}^{-}$but the visibility of color on the strip was much better for $1.0 \mathrm{mM}$. Similarly, the probe 3 was adsorbed on TLC plate and treated with the tested anions (Fig. 8b), the immediate naked-eye sensitive fluorescent color change from blue to green with $\mathrm{F}^{-}$and yellow with $\mathrm{CN}^{-}$under UV light (at $365 \mathrm{~nm}$ ) and unchanged with other anions suggested the applicability of probe to sense anion on a solid surface (Fig. 8b).

\subsection{Anion induced $\mathrm{CO}_{2}$ sensing}

The probe 3 contains an active - $\mathrm{NH}$ unit which can be utilized to detect $\mathrm{CO}_{2}$ by a chemical-based optical method. This is because the deprotonation of acidic - $\mathrm{NH}$ function of chromophore by a suitable anion like, $\mathrm{F}^{-}$generates negatively charged nitrogen, which may act as an efficient nucleophile to react with $\mathrm{CO}_{2}$. Therefore, to understand the potential applicability of probe 3 for anion induced $\mathrm{CO}_{2}$ sensing an attempt has been made and the change in typical photophysical behavior have been examined through the absorption and emission (i)

(a)

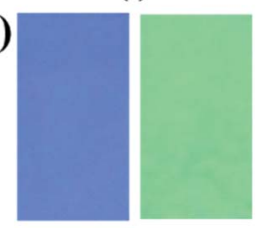

(b)

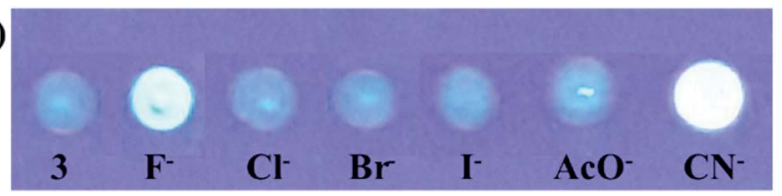

Fig. 8 (a) Fluorogenic (blue to yellowish green) response of 3 on paper strips containing different concentration of probe 3 ; (i) $5 \mathrm{mM}$, (ii) $2 \mathrm{mM}$, (iii) $1 \mathrm{mM}$ before and after addition of $\mathrm{F}^{-}$(i) $10 \times 10^{-5}$, (ii) $5.0 \times 10^{-5}$ and (iii) $1.0 \times 10^{-6} \mathrm{M}$. (b) Fluorogenic response of 3 with different anions on silica coated slides. 

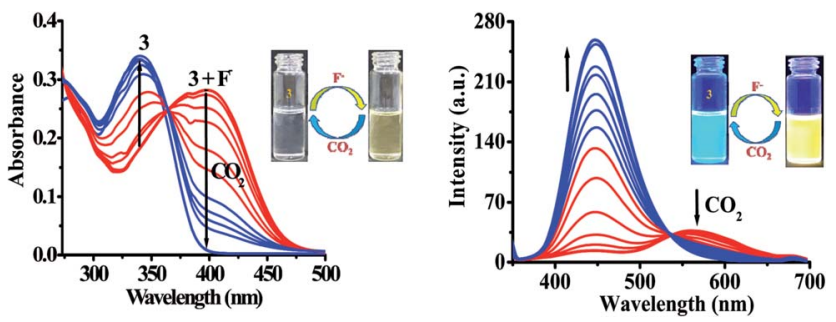

Fig. 9 Change in absorption and emission spectra of $3+\mathrm{F}^{-}$upon interaction with $\mathrm{CO}_{2}$ in DMSO. Images: change in color of 3 with $\mathrm{F}^{-}$ and $\mathrm{CO}_{2}$

spectroscopy (Fig. 9). First, the solution of probe 3 in DMSO was treated with TBAF to generate in situ an anion induced anionic probe, $3+\mathrm{F}^{-}$. Then, the volume of $\mathrm{CO}_{2}$ was increased to a solution of $3+\mathrm{F}^{-}$. It is interesting to mention that upon passing the $\mathrm{CO}_{2}$ to a solution of $3+\mathrm{F}^{-}$significant naked-eye sensitive color change were observed in which the original color of probe revived and, the typical absorption band for $3+$ $\mathrm{F}^{-}$centered, at $390 \mathrm{~nm}$ diminished with the revival of original absorption band of 3 at $340 \mathrm{~nm}$ along with formation of an isosbestic point at $365 \mathrm{~nm}$ (Fig. 9). Moreover, the observed emission intensity of $3+\mathrm{F}^{-}$at $453 \mathrm{~nm}$ and $556 \mathrm{~nm}$ (at $\lambda_{\text {ex }}=340$ $\mathrm{nm}$ ) upon increasing the volume of $\mathrm{CO}_{2}$ gas showed a gradual revival in emission intensity of 3 at $448 \mathrm{~nm}$ (Fig. 9) along with unique naked-eye sensitive colorimetric responses. The color of probe 3 changed from colorless to brown by $\mathrm{F}^{-}$revived to original color while under UV light the yellow color of $3+\mathrm{F}^{-}$ upon exposure with $\mathrm{CO}_{2}$ regenerated actual intense blue-green color of 3 (Fig. 9 images). Moreover, fluorescence titration data have been acquired to estimate the detection limit of $3+\mathrm{F}^{-}$ for $\mathrm{CO}_{2}$ and was found to be $0.36 \mu \mathrm{M}(\sim 16 \mathrm{ppb}$ ) (Fig. S18†). The significant colorimetric response displayed by 3 in the presence and absence of fluoride anion and carbon dioxide may be attributed to the formation of imidazolium hydrogen carbonate salt, generated from $\mathrm{N}-\mathrm{CO}_{2}$ adduct formed by the initial attack of negatively charged imidazolium ion to $\mathrm{CO}_{2}{ }^{29,53}$

\section{Conclusion}

In summary, probe 3 is found to detect trace amounts of $\mathrm{F}^{-}$anion in the solution and solid states with colorimetric and fluorometric responses due to variation in ICT process. Moreover, probe 3 has been utilized to detect $\mathrm{CO}_{2}$ by a chemical-based optical method. The in situ generated anionic species, $3+\mathrm{F}^{-}$ displayed unique colorimetric response along with revival in the typical photophysical properties of probe 3. Moreover, a remarkable solid state reaction resulting in an instantaneous change in color when 3 is brought in contact with crystals of TBAF, TBACN and TBOAc while it remained silent toward other tested $\left(\mathrm{Cl}^{-}, \mathrm{Br}^{-}\right.$ and $\mathrm{I}^{-}$) anions. Thus, the presence of the $-\mathrm{NH}$ group in the molecule is undoubtedly the centre of recognition of the anion as evident by the absence of sensing by the model compound, 4 . The ${ }^{1} \mathrm{H}$ NMR studies unequivocally supported about the deprotonation of moderately acidic imidazolyl $-\mathrm{NH}$ fragment in the presence of $\mathrm{F}^{-}$anion and confirmed the observed changes in the photophysical behavior of probe.

\section{Experimental section}

\subsection{Materials and chemicals}

All the reagents and solvents were purchased from SigmaAldrich Chemical Co. Pvt. Ltd. stored in a desiccator under vacuum containing self indicating silica, and used without any further purification. Solvents were purified prior to use. UV-vis absorption spectra were recorded on a Perkin Elmer Lambda35 UV-vis spectrophotometer using a quartz cuvette (path length $=1 \mathrm{~cm}$ ). Infrared (IR) spectra were recorded in potassium bromide $(\mathrm{KBr})$ on Varian-3100 FT-IR spectrometer. ${ }^{1} \mathrm{H}$ NMR spectra (chemical shifts in $\delta \mathrm{ppm}$ ) were recorded on a JEOL AL 300 FT-NMR (300 MHz) spectrometer, using tetramethylsilane (TMS) as internal standard. Fluorescence spectra were recorded on Varian eclipse Carry spectrofluorometer using a quartz cuvette (path length $=1 \mathrm{~cm}$ ) at 400 PMT voltage and slit width $5 \mathrm{~nm} / 5 \mathrm{~nm}$. All the spectroscopic experiments were carried out at room temperature. The stock solution of 3 $\left(1 \times 10^{-3} \mathrm{M}\right)$ were prepared in DMSO and diluted to obtain $10 \mu \mathrm{M}$ in DMSO for the absorption and fluorescence measurements, respectively. The stock solutions of different anions $(1 \times$ $10^{-1} \mathrm{M}$ ) were prepared by dissolving their tetrabutylammonium salt in DMSO. The anion interaction studies were performed by the addition of $1 \times 10^{-1} \mathrm{M}$ of different anions.

\subsection{Estimation of quantum yields}

The quantum yields of probe 3 and $3-\mathrm{F}^{-}$were estimated with respect to the quinine sulfate $(\Phi=0.54)$ as standard in $0.1 \mathrm{M}$ $\mathrm{H}_{2} \mathrm{SO}_{4}$ solution by secondary methods, using eqn (1).

$$
Q=Q_{R} \times I / I_{R} \times \mathrm{OD}_{R} / \mathrm{OD} \times n^{2} / n_{R}^{2}
$$

where $Q$ is the quantum yield, $I$ is the integrated intensity, OD is the optical density, and $n$ is the refractive index. The subscript $R$ refers to the reference fluorophore of known quantum yield.

\subsection{Estimation of binding constant}

The absorption and fluorescence experimental data were utilized to calculate association constants by Benesi-Hildebrand method (B-H method) employing eqn (2) for $1: 1$ stoichiometries.

$$
1 /\left(I-I_{0}\right)=1 /\left(I-I_{\mathrm{f}}\right)+1 / K\left(I-I_{\mathrm{f}}\right)[M]
$$

where $K$ is the association constant, $I$ is the absorbance/ fluorescence intensity of the free probe $3, I_{0}$ is the observed absorbance/fluorescence intensity of the $3-\mathrm{F}^{-}$complex, and $I_{\mathrm{f}}$ is the absorbance/fluorescence intensity at saturation level.

\subsection{Estimation of limit of detection}

The limit of detection (LOD) of 3 for $\mathrm{F}^{-}$was estimated by eqn (3). 


$$
\mathrm{LOD}=3 \sigma / m
$$

where, $\sigma$ stands for the standard deviation of blank solution of 3 and $m$ stands for calibration sensitivity toward $\mathrm{F}^{-}$ions in DMSO solution of 3 .

\subsection{Synthesis}

4.5.1 Synthesis of 1 . Benzil $(210 \mathrm{mg}, 1.0 \mathrm{mmol})$, ammonium acetate (231 $\mathrm{mg}, 4.0 \mathrm{mmol}), p$-bromobenzaldehyde $(185 \mathrm{mg}, 1.0 \mathrm{mmol})$, acetic acid $(10 \mathrm{ml})$ were taken in a round bottom flask and refluxed the reaction mixture for $4 \mathrm{~h}$. After completion of reaction (monitored on TLC) the solution was poured in crushed ice. The precipitate obtained was filtered and washed with water. ${ }^{1} \mathrm{H}$ NMR $\left(300 \mathrm{MHz}, \mathrm{CDCl}_{3}\right): \delta 12.77(\mathrm{~s}, 1 \mathrm{H})$, $8.04(\mathrm{~d}, 2 \mathrm{H}), 7.69$ (d, 2H), $7.51(\mathrm{~m}, 10 \mathrm{H}) . \mathrm{IR}(\mathrm{KBr}) \nu_{\max }\left(\mathrm{cm}^{-1}\right)$ : 500, 605, 695, 729, 765, 826, 914, 969, 1011, 1069, 1126, 1324, 1431, 1449, 1483, 1501, 1602, 3028.

4.5.2 Synthesis of 2 . Benzil ( $210 \mathrm{mg}, 1.0 \mathrm{mmol})$, aniline (93 mg, $1.0 \mathrm{mmol}$ ), ammonium acetate (231 mg, $4.0 \mathrm{mmol}), p$ bromobenzaldehyde (185 mg, $1.0 \mathrm{mmol})$, acetic acid $(10 \mathrm{ml})$ were taken in round bottom flask and refluxed for $4 \mathrm{~h}$. After completion of reaction (monitored on TLC), solution was cooled at room temperature then poured in crushed ice. The precipitate was filtered and washed with water. ${ }^{1} \mathrm{H}$ NMR $(300 \mathrm{MHz}$, $\left.\mathrm{CDCl}_{3}\right): \delta 7.58(\mathrm{~d}, 2 \mathrm{H}), 7.38(\mathrm{~d}, 2 \mathrm{H}), 7.35$ (m, 12). ${ }^{13} \mathrm{C}$ NMR $\delta$ (ppm): 161.79, 145.76, 136.90, 134.23, 131.28, 130.41, 130.31, 129.22, 128.27, 128.36, 128.18, 128.05, 126.71, 122.61. IR (KBr) $\nu_{\max }\left(\mathrm{cm}^{-1}\right): 654,695,765,830,960,1010,1074,1138,1410$, 1444, 1478, 1497, 1598, 3057.

4.5.3 Synthesis of 3-4. Compound 1 and $2(1.0 \mathrm{mmol})$ were taken separately in a two necked flask. To this 2-naphthyl boronic acid (2.2 mmol), catalytic amount of $\mathrm{Pd}(\mathrm{OAc})_{2}(0.5 \mathrm{mg}$, $0.1 \mathrm{~mol} \%)$, powdered $\mathrm{K}_{2} \mathrm{CO}_{3}(2.5 \mathrm{mmol})$ and $\mathrm{Bu}_{4} \mathrm{NBr}(1.0 \mathrm{mmol})$ were taken and nitrogen gas was passed to remove $\mathrm{O}_{2}$ from the reaction mixture. Now, the calculated amount of water $(2.5 \mathrm{ml})$ was added and stirred the reaction mixture for $1-2 \mathrm{~h}$ at $70{ }^{\circ} \mathrm{C}$. After completion of reaction (monitored on TLC) the reaction mixture was cool down to room temperature and diluted with water. The desired product was extracted with EtOAc. The collected organic portion was dried over anhydrous $\mathrm{Na}_{2} \mathrm{SO}_{4}$ and solvent was removed on rotary evaporator. The crude products were purified by column chromatography using EtOAc : Hexane $(0.5: 9.5, \mathrm{v} / \mathrm{v})$ as eluent to afford desired products.

4.5.4 Compound 3. Yield 71\%. ${ }^{1} \mathrm{H}$ NMR (300 $\left.\mathrm{MHz}, \mathrm{CDCl}_{3}\right)$, $\delta(\mathrm{ppm}): 12.79(\mathrm{~s}, 1 \mathrm{H}) 8.35(\mathrm{~m}, 4 \mathrm{H}), 8.01(\mathrm{~m}, 7 \mathrm{H}), 7.5(\mathrm{~m}, 10 \mathrm{H})$. ${ }^{13} \mathrm{C}$ NMR $\delta$ (ppm): 145.2, 139.4, 136.7, 134.9, 133.3, 132.4, 132.3, 130.6, 129.4, 128.6, 128.4, 128.2, 128.1, 127.4, 126.4, 126.2, 126.1, 125.7, 125.6, 125.1, 124.8. IR (KBr) $\nu_{\max }\left(\mathrm{cm}^{-1}\right): 696,750$, $765,815,1130,1233,1320,1384,1472,1493,1598,1628$. HRMS $m / z:[3+\mathrm{H}]^{+}$for $\mathrm{C}_{31} \mathrm{H}_{22} \mathrm{~N}_{2} 423.1056$ (calc. $=423.1083$ ).

4.5.5 Compound 4. Yield 76\%. ${ }^{1} \mathrm{H}$ NMR (300 $\mathrm{MHz}, \mathrm{CDCl}_{3}$ ), $\delta(\mathrm{ppm}): 7.92(\mathrm{~s}, 1 \mathrm{H}), 7.81(\mathrm{~d}, 1 \mathrm{H}), 7.63(\mathrm{~d}, 1 \mathrm{H}), 7.55(\mathrm{t}, 1 \mathrm{H}), 7.47$ $(\mathrm{d}, 1 \mathrm{H}), 7.39(\mathrm{~d}, 1 \mathrm{H}), 7.2(\mathrm{~m}, 15 \mathrm{H}) .{ }^{13} \mathrm{C}$ NMR $\delta(\mathrm{ppm}): 146.6$, 140.6 , 138.5, 137.6, 137.2, 134.4, 133.6, 132.7, 131.3, 131.1, $130.6,130.3,129.4,129.3,129.1,128.3,128.2$, 127.9, 127.5, 126.9, 126.3, 125.6, 125.2. IR (KBr) $\nu_{\max }\left(\mathrm{cm}^{-1}\right): 697,765,815$,
841, 960, 1026, 1073, 1261, 1369, 1446, 1482, 1497, 1598, 2853, 2923, 3057, 3417. HRMS $m / z:[4+\mathrm{H}]^{+}$for $\mathrm{C}_{37} \mathrm{H}_{26} \mathrm{~N}_{2} 499.2172$ (calc. $=499.2174)$.

\section{Acknowledgements}

The authors are thankful to the Council of Scientific and Industrial Research (CSIR), New Delhi for financial support (CSIR) 02(0199/14/EMR-II). The authors are also thankful to the Department of Science and Technology (under DST-FIST program), New Delhi for financial support to develop basic infrastructure facilities in our Department.

\section{References}

1 S. Y. Kim, J. Park, M. Koh, S. B. Park and J. Hong, Chem. Commun., 2009, 4735-4737.

2 P. D. Beer and P. A. Gale, Angew. Chem., Int. Ed., 2001, 40, 486-516.

3 P. G. Kostyuk, O. A. Krishtal and V. I. Pidoplichko, Nature, 1975, 257, 691-693.

4 S. Kubik, Chem. Soc. Rev., 2009, 38, 585-605.

5 D. Langmuir, Geochim. Cosmochim. Acta, 1978, 42, 547-569.

6 F. P. Schmidtchen and M. Berger, Chem. Rev., 1997, 97, 16091646.

7 Y. Jiang, X. Hu, J. Hu, H. Liu, H. Zhong and S. Liu, Macromolecules, 2011, 44, 8780-8790.

8 E. Gazzano, L. Bergandi, C. Riganti, E. Aldieri, S. Doublier, C. Costamagna, A. Bosia and D. Ghigo, Curr. Med. Chem., 2010, 17, 2431-2441.

9 M. C. Friesen, G. Benke, A. D. Monaco, M. Dennekamp, L. Fritschi, N. D. Klerk, J. L. Hoving, E. MacFarlane and M. R. Sim, Canc. Causes Contr., 2009, 20, 905-916.

10 P. Grandjean and P. J. Landrigan, Lancet, 2006, 368, 21672178.

11 O. Barbier, L. Arreola-Mendoza and L. M. Del Razo, Chem.Biol. Interact., 2010, 188, 319-333.

12 R. Sandhu, H. Lal, Z. S. Kundu and S. B. Kharb, Biol. Trace Elem. Res., 2011, 144, 1-5.

13 E. B. Bassin, D. Wypij and R. B. Davis, Canc. Causes Contr., 2006, 17, 421-428.

14 Y. Zhou, J. F. Zhang and J. Yoon, Chem. Rev., 2014, 114, 55115571.

15 A. N. Katruzov, T. G. Nikitina and L. N. Moskvin, J. Anal. Chem., 1998, 53, 173-177.

16 M. S. Frant and J. W. Ross, Science, 1966, 154, 1553.

17 H. Hara and C. C. Huang, Anal. Chim. Acta, 1997, 338, 141147.

18 R. Bodor, V. Madajova, M. Masar, M. Johnck, B. Stanislawski and D. Kaniansky, J. Chromatogr. A, 2001, 916, 155-165.

19 (a) M. Wenzel, J. R. Hiscock and P. A. Gale, Chem. Soc. Rev., 2012, 41, 480-520; (b) X. Li, X. Gao, W. Shi and H. Ma, Chem. Rev., 2014, 114, 590-659; (c) Y. Yang, Q. Zhao, W. Feng and F. Li, Chem. Rev., 2013, 113, 192-270; (d) S. K. Kim and J. L. Sessler, Chem. Soc. Rev., 2010, 39, 3784-3809; (e) J. L. Sessler, A. Andrievsky and J. W. Genge, Advances in 
Supramolecular Chemistry, ed. G.W. Gokel, 1997, vol. 4, pp. 97-142.

20 (a) C. R. Maldonado, A. Touceda-Varela, A. C. Jonesa and J. C. Mareque-Rivas, Chem. Commun., 2011, 47, 1170011702; (b) H. J. Kim, H. Lee, J. H. Lee, D. H. Choi, J. H. Jung and J. S. Kim, Chem. Commun., 2011, 47, 1091810920; (c) J. J. Lee, G. J. Park, Y. W. Choi, G. R. You, Y. S. Kim, S. Y. Lee and C. Kim, Sens. Actuators, B, 2015, 207, 123-132; (d) S. S. Razi, R. Ali, P. Srivastava, M. Shahid and A. Misra, RSC Adv., 2014, 4, 22308-22317.

21 (a) A. Aydogan, D. J. Coady, V. M. Lynch, A. Akar, M. Marquez, C. W. Bielawski and J. L. Sessler, Chem. Commun., 2008, 1455-1457; (b) C. Bhaumik, D. Saha, S. Das and S. Baitalik, Inorg. Chem., 2011, 50, 12586125600; (c) D. Maity, S. Das, S. Mardanya and S. Baitalik, Inorg. Chem., 2013, 52, 6820-6838; (d) N. Kumari, S. Jha and S. Bhattacharya, J. Org. Chem., 2011, 76, 8215-8222; (e) M. Cametti and K. Rissanen, Chem. Commun., 2009, 28092829.

22 M. Cametti and K. Rissanenb, Chem. Soc. Rev., 2013, 42, 2016-2038.

23 A. P. de Silva, H. Q. N. Gunaratne, T. Gunnlaugsson, A. J. M. Huxley, C. P. McCoy, J. D. Rademacher and T. E. Rice, Chem. Rev., 1997, 97, 1515-1566.

24 J. L. Sessler, S. Camiolo and P. A. Gale, Coord. Chem. Rev., 2003, 240, 17-55.

25 K. Choi and A. D. Hamilton, Coord. Chem. Rev., 2003, 240, 101-110.

26 K. M. K. Swamy, Y. J. Lee, H. N. Lee, J. Chun, Y. Kim, S.-J. Kim and J. Yoon, J. Org. Chem., 2006, 71, 8626-8628.

27 X. Y. Liu, D. R. Bai and S. Wang, Angew. Chem., Int. Ed., 2006, 45, 5475-5478.

28 (a) J. Wu, B. Kwon, W. Liu, E. V. Anslyn, P. Wang and J. S. Kim, Chem. Rev., 2015, 115, 7893-7943; (b) R. Martínez-Máñez and F. Sancenón, Chem. Rev., 2003, 103, 4419-4476; (c) Y. Zhou, J. F. Zhang and J. Yoon, Chem. Rev., 2014, 114, 5511-5571.

29 Z. Guo, N. R. Song, J. H. Moon, M. Kim, E. J. Jun, J. Choi, J. Y. Lee, C. W. Bielawski, J. L. Sessler and J. Yoon, J. Am. Chem. Soc., 2012, 134, 17846-17849.

30 T. Gunnlaugsson, P. E. Kruger, P. Jensen, F. M. Pfeffer and G. M. Hussey, Tetrahedron Lett., 2003, 44, 8909-8913.

31 X. Xie, M. Pawlak, M. Tercier-Waeber and E. Bakker, Anal. Chem., 2012, 84, 3163-3169.

32 Y. Liu, Y. Tang, N. N. Barashkov, I. S. Irgibaeva, J. W. Y. Lam, R. Hu, D. Birimzhanova, Y. Yu and B. Z. Tang, J. Am. Chem. Soc., 2010, 132, 13951-13953.

33 R. N. Dansby-Sparks, J. Jin, S. J. Mechery, U. Sampathkumaran, T. W. Owen, B. D. Yu, K. Goswami, K. Hong, J. Grant and Z.-L. Xue, Anal. Chem., 2010, 82, 593-600.

34 M. Ishida, P. Kim, J. Choi, J. Yoon, D. Kim and J. L. Sessler, Chem. Commun., 2013, 49, 6950-6952.

35 R. Ali, T. Lang, S. M. Saler, R. J. Meier and O. S. Wolfbeis, Anal. Chem., 2011, 83, 2846-2851.
36 D. Wencel, J. P. Moore, N. Stevernson and C. McDonagh, Anal. Bioanal. Chem., 2010, 398, 1899-1907.

37 Q. Xu, S. Lee, Y. Cho, M. H. Kim, J. Bouffard and J. Yoon, J. Am. Chem. Soc., 2013, 135, 17751-17754.

38 M. Lee, S. Jo, D. Lee, Z. Xu and J. Yoon, Dyes Pigm., 2015, 120, 288-292.

39 M. Lee, J. H. Moon, K. M. K. Swamy, Y. Jeong, G. Kim, J. Choi, J. Y. Lee and J. Yoon, Sens. Actuators, B, 2014, 199, 369-376.

40 K. D. Prasad, N. Venkataramaiah and T. N. G. Row, Cryst. Growth Des., 2014, 14, 2118-2122.

41 (a) S. S. Razi, P. Srivastava, R. Ali, R. C. Gupta, S. K. Dwivedi and A. Misra, Sens. Actuators, B, 2015, 209, 162-171; (b) R. Ali, S. S. Razi, R. C. Gupta, S. K. Dwivedi and A. Misra, New J. Chem., 2016, 40, 162-170.

42 (a) S. Liu, W. Wang, A. Briseno, S. Mannsfeld and Z. Bao, Adv. Mater., 2009, 21, 1217-1232; (b) D. Braga and G. Horowitz, Adv. Mater., 2009, 21, 1473-1486; (c) S. Lee, S. Hotta and F. Nakanishi, J. Phys. Chem. A, 2000, 104, 1827-1833; (d) S. Kanazawa, M. Ichikawa, Y. Fujita, R. Koike, T. Koyama and Y. Taniguchi, Org. Electron., 2008, 9, 425-431; (e) R. Ali, S. S. Razi, P. Srivastava and A. Misra, Sens. Actuators, $B, 2015,221,1236-1247$.

43 S. Park, J. E. Kwon, S. H. Kim, J. Seo, K. Chung, S. Y. Park, D. J. Jang, B. M. Medina, J. Gierschner and S. Y. Park, J. Am. Chem. Soc., 2009, 131, 14043-14049.

44 D. Badone, M. Baroni, R. Cardamone, A. Ielmini and U. Guzzi, J. Org. Chem., 1997, 62, 7170-7173.

45 P. Dydio, D. Lichosyt and J. Jurczak, Chem. Soc. Rev., 2011, 40, 2971-2985.

46 M. Shahid, P. Srivastava and A. Misra, New J. Chem., 2011, 35, 1690-1700.

47 A. Misra, M. Shahid and P. Dwivedi, Talanta, 2009, 80, 532538.

48 A. Misra, M. Shahid and P. Srivastava, Sens. Actuators, B, 2012, 169, 327-340.

49 H. A. Benesi and J. H. Hildebrand, J. Am. Chem. Soc., 1949, 71, 2703-2707.

50 A. Misra, P. Srivastava and M. Shahid, Analyst, 2012, 137, 3470-3478.

51 M. J. Frisch, G. W. Truncks and H. B. Schlegel, GAUSSIAN 03, Revision E.01; Gaussian, Wallingford, CT, 2007.

52 (a) F. G. Bordwell, Acc. Chem. Res., 1988, 21, 456-463; (b) J. V. Ros-Lis, R. Martinez-Manez, F. Sancenon, J. Soto, K. Rurack and H. Weißhoff, Eur. J. Org. Chem., 2007, 24492458.

53 (a) M. Boiocchi, L. D. Boca, D. Esteban-Gómez, L. Fabbrizzi, M. Licchelli and E. Monzani, Chem.-Eur. J., 2005, 11, 30973104; (b) V. Amendola, M. Boiocchi, L. Fabbrizzi and A. Palchetti, Chem.-Eur. J., 2005, 11, 5648-5660; (c) D. Esteban-Gómez, L. Fabbrizzi, M. Licchelli and D. Sacchi, J. Mater. Chem., 2005, 15, 2670-2675; (d) D. Esteban-Gómez, L. Fabbrizzi and M. Licchelli, J. Org. Chem., 2005, 70, 5717-5720. 